Article

\title{
Beyond CC398: Characterisation of Other Tetracycline and Methicillin-Resistant Staphylococcus aureus Genetic Lineages Circulating in Spanish Hospitals
}

\author{
Sara Ceballos ${ }^{1}$, Carmen Lozano ${ }^{1}$ (D), Carmen Aspiroz ${ }^{2}$, Laura Ruiz-Ripa ${ }^{1}$, Paula Eguizábal ${ }^{1}$, \\ Allelen Campaña-Burguet ${ }^{1}$, Emilia Cercenado ${ }^{3} \mathbb{D}$, Ana Isabel López-Calleja ${ }^{4}$, Javier Castillo ${ }^{5}$, \\ Jose Manuel Azcona-Gutiérrez ${ }^{6}{ }^{(D)}$, Luis Torres ${ }^{7}$, Jorge Calvo ${ }^{8}{ }^{D}$, Carmen Martin ${ }^{9}$, María Navarro ${ }^{10}$, \\ Myriam Zarazaga $^{1}$, Carmen Torres ${ }^{1, *(1)}$ and the Study Group of Clinical LA-MRSA ${ }^{\dagger}$
}

check for updates

Citation: Ceballos, S.; Lozano, C.; Aspiroz, C.; Ruiz-Ripa, L.; Eguizábal, P.; Campaña-Burguet, A.; Cercenado, E.; López-Calleja, A.I.; Castillo, J.; Azcona-Gutiérrez, J.M.; et al. Beyond CC398: Characterisation of Other Tetracycline and Methicillin-Resistant Staphylococcus aureus Genetic Lineages Circulating in Spanish Hospitals. Pathogens 2022, 11, 307. https://doi.org/10.3390/ pathogens 11030307

Academic Editor: Jilei Zhang

Received: 7 February 2022 Accepted: 25 February 2022 Published: 1 March 2022

Publisher's Note: MDPI stays neutral with regard to jurisdictional claims in published maps and institutional affiliations.

Copyright: (c) 2022 by the authors. Licensee MDPI, Basel, Switzerland. This article is an open access article distributed under the terms and conditions of the Creative Commons Attribution (CC BY) license (https:// creativecommons.org/licenses/by/ $4.0 /)$.
1 Area Bioquímica y Biología Molecular, Universidad de La Rioja, 26006 Logroño, Spain; saraceballos@hotmail.es (S.C.); carmen.lozano@unirioja.es (C.L.); laura_ruiz_10@hotmail.com (L.R.-R.); paulaeguimar@gmail.com (P.E.); allelencampanaburguet@gmail.com (A.C.-B.); myriam.zarazaga@unirioja.es (M.Z.)

2 Servicio de Microbiología, Hospital Royo Villanova, 50015 Zaragoza, Spain; carmen.aspiroz@gmail.com 3 Servicio de Microbiología y Enfermedades Infecciosas, Hospital General Universitario Gregorio Marañón, CIBERES (CIBER de Enfermedades Respiratorias), 28007 Madrid, Spain; emilia.cercenado@salud.madrid.org

4 Hospital Universitario Miguel Servet/IIS Aragón, 50009 Zaragoza, Spain; ailopezcal@salud.aragon.es

5 Hospital Clínico Universitario Lozano Blesa, 50009 Zaragoza, Spain; macarios@unizar.es

6 Hospital San Pedro, 26006 Logroño, Spain; jmazcona@riojasalud.es

7 Hospital San Jorge, 22004 Huesca, Spain; ltorres@salud.aragon.es

8 Hospital Universitario Marqués de Valdecilla, CIBERINFEC (CIBER de Enfermedades Infecciosas, Instituto de Salud Carlos III), 39008 Santander, Spain; jorge.calvo@scsalud.es

9 Complejo Hospitalario de Navarra, 31008 Pamplona, Spain; carmen.martin.salas@navarra.es

10 Hospital Universitari de Vic, 08500 Vic, Spain; mnavarro@chv.cat

* Correspondence: carmen.torres@unirioja.es; Tel.: +34-9412-99750; Fax: +34-9412-99721

+ Study Group of Clinical LA-MRSA are listed in the Acknowledgment section.

Abstract: Tetracycline resistance $\left(\mathrm{Tet}^{\mathrm{R}}\right)$ has been evidenced as a good phenotypic marker for detection of livestock-associated methicillin-resistant Staphylococcus aureus (LA-MRSA) isolates of the clonal complex CC398. The aim of this study was to characterise a collection of $95 \mathrm{Tet}^{\mathrm{R}}$-MRSA isolates, not belonging to the lineage CC398, that were obtained in a previous multicentre study, to detect other MRSA clonal complexes that could be associated with this phenotypic $\operatorname{Tet}^{R}$ marker. The $\operatorname{Tet}^{\mathrm{R}}$ MRSA isolates were recovered from 20 Spanish hospitals during 2016 and they were characterised to determine their antimicrobial resistance and virulence phenotypes/genotypes as well as the presence of the immune evasion cluster (IEC). A high proportion of isolates belonging to the CC1 lineage (46\%) were observed, as well as to the CC5, CC8 and CC45 lineages (11\% each one). Thirty-two different spa-types were identified, being predominantly CC1-t127 (40\%) and CC45-t1081 (11\%). The IEC system (with the gene scn as marker) was present in $73 \%$ of isolates and $16 \%$ produced the Panton Valentine leucocidin (PVL). A high proportion of MRSA-CC1 isolates were scn-negative (38.6\%) and $52.9 \%$ of them were blaZ-negative. A multidrug resistance (MDR) phenotype was identified in $86 \%$ of MRSA isolates. The knowledge of other Tet $^{\mathrm{R}}$-MRSA genetic lineages, in addition to CC398, is highly relevant, since most of them were MDR and some of them presented important virulence factors. Strains potentially associated with livestock (as the subpopulation CC1-t127-scn-negative) or with humans (as the CC45 lineage or the subpopulation CC1-scn-positive) have been found in this study. The use of tetracycline-resistance for detection, not only of CC398 but also of other LA-MRSA lineages should be tracked in the future.

Keywords: MRSA; tetracycline resistance; CC398; CC1; t127; multicentre study 


\section{Introduction}

Staphylococcus aureus is a common bacterium in human and animal regular microbiota, particularly present in the nose and on the skin. However, S. aureus can be an important opportunistic pathogen capable of causing anything from mild skin to life-threatening infections. S. aureus is also able to acquire multiple antimicrobial resistance mechanisms, and standing out amongst them, methicillin-resistant $S$. aureus (MRSA) isolates because of its resistance to almost all $\beta$-lactams [1].

Different clonal lineages have been initially proposed to be directly related to the environment in which they are found. In this way, we classically found hospital-associated (HA) or community-acquired (CA) MRSA. Nevertheless, nowadays this line of distinction within groups is becoming more and more blurred.

Newer livestock-associated (LA) MRSA lineages, genetically different from human isolates and closely related to farm animals, have been found more regularly in the healthcare system [2]. During the last decade, livestock have been considered to be a great reservoir of MRSA with high potential of zoonotic transmission to humans [3]. It has been observed that the spread of LA-MRSA from animals to humans occurs frequently and that livestock workers present a high risk for LA-MRSA colonisation and subsequent infection [4]. The abusive use of antimicrobials like tetracycline in food production animals leads to the selective pressure of tetracycline-resistant $\left(\mathrm{Tet}^{\mathrm{R}}\right)$ LA-MRSA isolates [5]. The most common LA-MRSA lineage in Europe belongs to the clonal complex CC398. Tet ${ }^{R}$ is one of its most outstanding features, a few atypical tetracycline-susceptible LA-MRSA strains have been detected [6], and this phenotype is commonly used for its detection [7]. LA-MRSA CC398 is related to pig farming and contact with these animals seems to be the driving force for human transmission. However, more and more often the frequent appearance of LA-MRSA cases in people without livestock contact is being reported [7].

Other LA-MRSA genetic lineages have been also related to animals and they are gaining relevance in the public health landscape [8-11]. While some of them have been also associated with pig farming (CC1, CC9 or CC97), others have been found in cattle (CC130, CC425), horses (CC8) and/or poultry (CC5) [12]. Nevertheless, frequently many of these clonal lineages have been detected in different animal hosts [12] and transmission among different livestock animals has been suggested [13].

In a previous study, a collection of $232 \mathrm{Tet}^{\mathrm{R}}$-MRSA isolates was obtained during a six-month period from 20 Spanish hospitals located in regions with different pig farming densities, in order to seek for potential CC398 isolates. Almost $60 \%$ of the Tet ${ }^{R}$-MRSA isolates corresponded to the lineage CC398 ( $\mathrm{n}=137$ isolates), and a significant correlation was evidenced between the rate of MRSA CC398 detected in a hospital and the pig farming density in the adjoining region [14]. The non-CC398 isolates of this collection $(n=95)$ were not further characterised, and the unique data known were that $46 \%$ of them corresponded to the clonal complex CC1 [14]. The Sequence Type (ST) 1 belonging to CC1 lineage, producer of the Panton-Valentine leucocidin (PVL), is well recognised as a CA-MRSA in human infections, also known as USA400, and common in the USA [15]. In Europe, some cases of this PVL-positive clone have been reported, for instance in Italy [16] or Denmark [17]. Nevertheless, a different CA-MRSA ST1 subpopulation (presenting the spa-type t127) has been described in the United Kingdom, highlighting its lack of PVL production $[18,19]$. The spa-type 127 has been associated with LA-MRSA isolates and, when recovered from pigs, the isolates are generally IEC negative [20]. However, some studies have reported the presence of MRSA spa-type t127 in isolates of farmed animal origin (especially of bovine) with similar characteristics to the human clade, such as the presence of the genes scn, sak, sea or sat [20,21]. Several reports have highlighted the presence of MRSA-CC1-t127 isolates colonising pigs and also colonising or causing infections in people in contact with these farm animals $[9,11,22]$.

Considering the results obtained in the previous study, in which $\mathrm{Tet}^{\mathrm{R}}$ was evidenced as a good phenotypic marker for LA-MRSA detection of the lineage CC398, the possibility of finding other LA-MRSA clonal lineages was analysed. The aim of the present 
study was to carry out the complete characterisation of the referred collection of the 95 non-CC398 Tet $^{\mathrm{R}}$-MRSA isolates by analysing their antimicrobial resistance and virulence phenotypes and genotypes, as well as the presence of the IEC system and their corresponding clonal lineages.

\section{Results}

\subsection{Molecular Characterisation of MRSA Isolates}

Thirty-two different spa-types were identified among the $95 \mathrm{Tet}^{\mathrm{R}}$-MRSA isolates analysed (Tables 1 and 2), with a40\% of them belonging to spa-type t127, followed by $\mathrm{t} 1081$ $(10.5 \%), \mathrm{t} 148(6.3 \%), \mathrm{t} 002(5.3 \%)$, and others with only one to three isolates per spa type $(37.9 \%)$. Three new spa-types were detected in this study: t17234, t1723, and $\mathrm{t} 17236$.

The spa types were ascribed to nine different clonal complexes (CC1, CC5, CC7, CC8, CC30, CC45, CC80, CC88, CC121), and to two sequence types (ST2625 and a ST registered as ST5427, a single-locus variant of ST2050 with a different aroE allele) (Tables 1 and 2). The most prevalent CC was CC1 (46\%), including the following spa-types (number of isolates): t127 (38), t1381 (2), t174 (1), t693 (1), t1784 (1), and t2207 (1) (Table 3). The CC1 was present in 14 out of the 17 participant hospitals (Table 1 ). The SCCmec type was analysed in all 38 CC1-t127 isolates and all of them belonged to type IVa.

\subsection{Sample Origin}

According to the origin of MRSA isolates, $80 \%$ were obtained from clinical samples and the remaining $20 \%$ from epidemiological surveillance (ES) samples. Within clinical isolates, $64.5 \%$ were obtained from samples of skin and soft tissue infections (SSTI), 18.4\% from respiratory tract infections (RTI), 5.3\% from surgical site infections (SSI), 6.5\% from urinary tract infections (UTI) and 5.3\% from blood. Table 2 shows the distribution of the different sample origins according to the spa-types detected in the study.

\subsection{Presence of the IEC and PVL Toxin}

The IEC system (scn-positive) was present in 69/95 (73\%) MRSA isolates analysed (Tables 1 and 2). The CC1, CC5, CC8 and CC30 lineages contained both IEC-positive and IEC-negative isolates. However, all CC45, CC80, CC88 and CC121 lineages included only IEC-positive isolates (Figure 1A). Considering only the 38 isolates with the prevalent CC1t127 lineage, 39\% were scn-negative and, of them, 60\% were recovered from SSTI (compared to scn-positive isolates where $34 \%$ were IPPB) (Table 3). There was a statistically significant difference ( $p=0.022$ ) between the proportion of scn-negative isolates considering CC1 isolates and the rest of isolates included in other CCs (Figure 2A).

The PVL virulence factor was detected in 15 MRSA isolates (16\%) (Table 2 and Figure 1B), with $40 \%$ of PVL-producer isolates recovered from SSTI, $27 \%$ from RTI and $13 \%$ from ES samples, among others (Table 2). Only two CC1 isolates (spa-types t127 and t1784) were PVL-positive (Table 3). Moreover, three PVL-positive isolates were negative for the IEC, these isolates belonging to CC8-t148, CC30-t665 and t4725 (Figure 1B).

\subsection{Multidrug Resistance (MDR) Phenotypes}

The collection of MRSA isolates analysed was resistant to different groups of antimicrobial agents (Figure 3A). A MDR phenotype was present in 86\% (82/95) of studied MRSA isolates, with $24 \%$ of them resistant to three different families, 38\% resistant to four, $18 \%$ resistant to five, $16 \%$ resistant to six and $4 \%$ resistant to seven or more different antimicrobial families. Among non-multidrug resistant isolates, 13 isolates were resistant to $\beta$-lactams and tetracycline and $69 \%$ of them belonged to lineage CC1 (Table 3). 
Table 1. Distribution of non-CC398 Tet $^{\mathrm{R}}$-MRSA isolates among hospitals and genetic lineages detected.

\begin{tabular}{|c|c|c|c|c|c|c|c|c|c|c|c|c|c|c|}
\hline \multirow[t]{2}{*}{$\begin{array}{l}\text { Hospital } \\
\text { Number }\end{array}$} & \multicolumn{6}{|c|}{ Number of Isolates } & \multicolumn{3}{|c|}{ Rates (\%) } & \multicolumn{2}{|c|}{ Density (per $\mathbf{k m}^{2}$ ) } & \multicolumn{2}{|c|}{$\begin{array}{c}s c n^{c} \\
\text { (Number of } \\
\text { Non CC398 } \\
\text { Isolates) } \\
\end{array}$} & \multirow{2}{*}{$\begin{array}{c}\text { Clonal Complex } \\
\text { (Number of } \\
\text { Non-CC398 } \\
\text { Isolates) }\end{array}$} \\
\hline & MRSA & $\begin{array}{l}\text { Tet }^{R_{-}} \\
\text {MRSA }\end{array}$ & $\begin{array}{l}\text { Tet }^{\mathrm{R}}- \\
\text { MRSA } \\
\text { CC398 }\end{array}$ & $\begin{array}{l}\text { Tet }{ }^{\mathrm{R}} \text {-MRSA } \\
\text { Non-CC398 }\end{array}$ & $\begin{array}{c}\text { Tet }^{\mathrm{R}}- \\
\text { MRSA } \\
\text { CC1 }\end{array}$ & $\begin{array}{l}\text { Tet }^{\mathrm{R}}- \\
\text { MRSA/ } \\
\text { MRSA }\end{array}$ & $\begin{array}{r}\text { Tet }^{\mathrm{R}} \text {-MRSA } \\
\text { Non-CC398 } \\
/ \text { Tet }^{\mathrm{R}} \text {-MRSA }\end{array}$ & $\begin{array}{c}\text { Tet }^{\mathrm{R}} \text {-MRSA } \\
\text { CC1/Tet } \\
\text { MRSA } \\
\text { MRSA }\end{array}$ & $\begin{array}{c}\text { Tet }^{\mathrm{R}} \text {-MRSA } \\
\text { CC1/Tet } \\
\text { MRS } \\
\text { Non-CC398 }\end{array}$ & Pigs & Inhabitants & + & - & \\
\hline $\mathrm{H} 1$ & 87 & 33 & 27 & 6 & 6 & 38 & 18 & 18 & 100 & 247.46 & 717.36 & 6 & 0 & CC1 (6) \\
\hline $\mathrm{H} 2$ & 135 & 20 & 19 & 1 & 0 & 15 & 5 & 0 & 0 & 217.68 & 14.05 & 1 & 0 & CC45 (1) \\
\hline $\mathrm{H} 3$ & 328 & 24 & 15 & 9 & 1 & 7 & 38 & 4 & 11 & 217.68 & 14.05 & 8 & 1 & CC1 (1), CC45 (8) \\
\hline $\mathrm{H} 4$ & 251 & 34 & 18 & 16 & 12 & 14 & 47 & 35 & 75 & 142.66 & 55.20 & 8 & 8 & $\begin{array}{l}\text { CC1 (12), CC5 (1), } \\
\text { CC8 (2), CC88 (1) } \\
\text { CC1 (5), CC5 (1), }\end{array}$ \\
\hline H5 & 175 & 20 & 9 & 11 & 5 & 11 & 55 & 25 & 45 & 142.66 & 55.20 & 10 & 1 & $\begin{array}{c}\text { CC8 (1), CC45 (1), } \\
\text { ST5427 (1), } \\
\text { unknown (2) }\end{array}$ \\
\hline H6 & 76 & 9 & 7 & 2 & 2 & 12 & 22 & 22 & 100 & 142.66 & 55.20 & 1 & 1 & CC1 $(2)$ \\
\hline H7 & 42 & 6 & 3 & 3 & 2 & 14 & 50 & 33 & 67 & 142.66 & 55.20 & 1 & 2 & CC1 (2), CC80 (1) \\
\hline H8 & 36 & 4 & 4 & 0 & 0 & 11 & 0 & 0 & 0 & 69.97 & 9.15 & - & - & $4-$ \\
\hline $\mathrm{H} 9$ & 36 & 2 & 2 & 0 & 0 & 6 & 0 & 0 & 0 & 50.89 & 61.90 & - & - & - \\
\hline $\mathrm{H} 10$ & 206 & 14 & 7 & 7 & 3 & 7 & 50 & 21 & 43 & 50.89 & 61.90 & 5 & 2 & $\begin{array}{l}\text { CC1 (3), CC8 (1), } \\
\text { CC } 80 \text { (1), CC121 }\end{array}$ \\
\hline H11 & 84 & 7 & 3 & 4 & 2 & 8 & 57 & 29 & 50 & 42.10 & 138.18 & 3 & 1 & $\begin{array}{l}\text { (1), unknown (1) } \\
\text { CC1 (2), CC8 (2) }\end{array}$ \\
\hline H12 & 220 & 6 & 3 & 3 & 1 & 3 & 50 & 17 & 33 & 27.66 & 25.54 & 3 & 0 & $\begin{array}{l}\text { CC1 (1), CC8 (1), } \\
\text { unknown (1) }\end{array}$ \\
\hline H15 & 334 & 5 & 5 & 0 & 0 & 1 & 0 & 0 & 0 & 40.99 & 107.53 & - & - & \\
\hline H16 & 130 & 7 & 3 & 4 & 0 & 5 & 57 & 0 & 0 & 30.56 & 360.18 & 3 & 1 & $\begin{array}{c}\text { CC8 (1), CC88 (1), } \\
\text { unknown (2) } \\
\text { CC1 (4), CC5 (2), }\end{array}$ \\
\hline H17 & 315 & 12 & 0 & 12 & 4 & 4 & 100 & 33 & 33 & 20.85 & 810.66 & 12 & 0 & $\begin{array}{l}\text { CC7 (1), ST2625 } \\
\text { (2), unknown (3) }\end{array}$ \\
\hline $\mathrm{H} 18$ & 277 & 7 & 3 & 4 & 2 & 3 & 57 & 29 & 50 & 20.19 & 517.95 & 0 & 4 & $\begin{array}{c}\text { CC1 (2), CC5 (1), } \\
\text { CC } 30(1)\end{array}$ \\
\hline H19 & 371 & 13 & 5 & 8 & 2 & 4 & 62 & 15 & 25 & 00.45 & 109.06 & 7 & 1 & $\begin{array}{c}\text { CC1 (2), CC5 (3), } \\
\text { CC8 (1), CC30(1), } \\
\text { CC } 88(1)\end{array}$ \\
\hline $\mathrm{H} 20$ & 126 & 1 & 0 & 1 & 1 & 1 & 100 & 100 & 100 & 00.45 & 109.06 & 1 & 0 & CC1 (1) \\
\hline Total & 3383 & 232 & $137^{\mathrm{b}}$ & 95 & 45 & 6.8 & 40.9 & 13.4 & 47.4 & - & - & 69 & 26 & - \\
\hline
\end{tabular}

${ }^{a}$ Numeric code used for the analysed hospitals (H). H1: H. Universitari de Vic; H2: H. de Barbastro; H3: H. San Jorge; H4: H. Universitario Miguel Servet; H5: H. Universitario Lozano Blesa; H6: H. Royo Villanova; H7: H. Ernest Lluch Martin; H8: H. de Alcañiz; H9: Clínica Universitaria de Navarra; H10: Complejo Hospitalario de Navarra; H11: H. Virgen Macarena; H12: H. Universitario de Burgos; H13: H. Santiago Apóstol; H14: H. San Pedro; H15: H. Universitario de Álava; H16: H. Universitario de Donostia; H17: H. Universitario Gregorio Marañón; H18: H. de Galdakao; H19: H. Marqués de Valdecilla; H20: H. Sierrallana. ${ }^{b}$ These strains were previously characterised [14]. ${ }^{c}$ scn: presence or absence of the scn gene as marker of the immune evasion cluster (IEC). 
Table 2. Molecular characterisation of the non-C398 Tet $^{\mathrm{R}}$-MRSA collection $(\mathrm{n}=95)$ attending to their spa-types and sample origin.

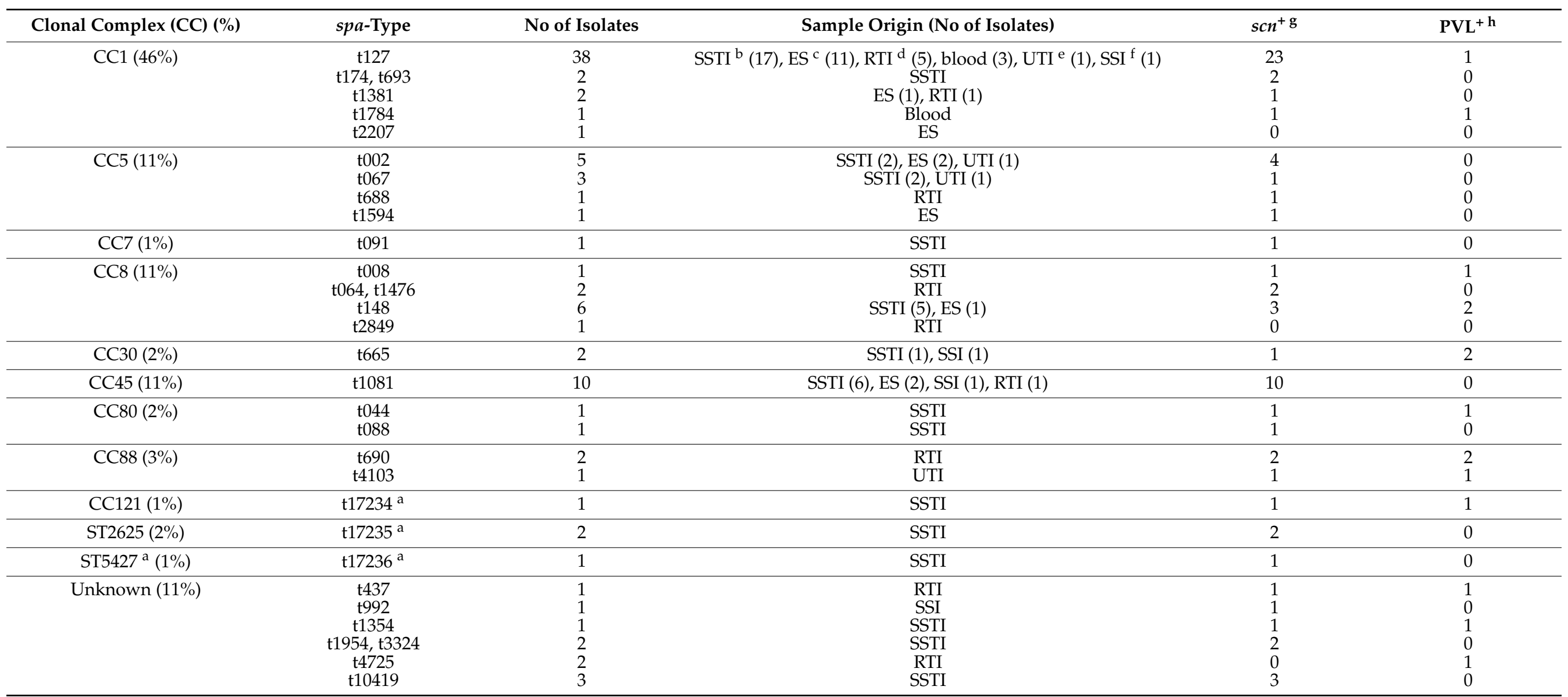

${ }^{a}$ New spa-type or sequence type; ${ }^{b}$ SSTI: skin and soft tissue infections; ${ }^{c}$ ES: epidemiological surveillance; ${ }^{\text {d }}$ RTI: respiratory tract infections; ${ }^{\mathrm{e}}$ UTI: urinary tract infections; ${ }^{\mathrm{f}}$ SSI: surgical site infection; $\mathrm{g}_{\mathrm{SCn}^{+}}$: presence of the $\mathrm{scn}$ gene as marker of the immune evasion cluster (IEC); ${ }^{\mathrm{h}} \mathrm{PVL}^{+}$: presence of the genes encoding Panton-Valentine leukocidin. 
Table 3. Characterisation of tetracycline-resistant CC1 MRSA isolates $(\mathrm{n}=44)$

\begin{tabular}{|c|c|c|c|c|c|c|}
\hline \multirow{2}{*}{$\begin{array}{c}\text { spa-Type } \\
\text { (No of Isolates) }\end{array}$} & \multicolumn{2}{|c|}{ Antimicrobial Resistance (Non Beta-Lactams) } & \multirow[b]{2}{*}{$\begin{array}{c}\text { No of blaZ } \\
\text { Positive Isolates }\end{array}$} & \multirow{2}{*}{$\begin{array}{c}\text { No of } s c n \\
\text { Negative Isolates }\end{array}$} & \multirow[b]{2}{*}{$\begin{array}{c}\text { No of PVL } \\
\text { Positive Isolates }\end{array}$} & \multirow[b]{2}{*}{ Origin (No of Isolates) ${ }^{c}$} \\
\hline & $\begin{array}{c}\text { Phenotype a } \\
\text { (No of Isolates) }\end{array}$ & Genotype ${ }^{b}$ & & & & \\
\hline \multirow{7}{*}{ t127 (38) } & TET (5) & tetK & 4 & 1 & 0 & ES (5) \\
\hline & ERY-TET (6) & tet $L^{1}$, tetK, $m s r A$ & 6 & 1 & 0 & RTI (1), SSTI (5) \\
\hline & CLI-ERY-TET (17) & tet $K, e r m B^{2}, e r m C^{15}, m s r A^{4}, l_{s a} B^{1}$ & 11 & 8 & 1 & ES (3), RTI (3), SSTI (7), SSI (1), blood (3) \\
\hline & CIP-TET (1) & tetK & 1 & 0 & 0 & ES (1) \\
\hline & ERY-CIP-TET (1) & tetK, $m s r A$ & 1 & 1 & 0 & RTI (1) \\
\hline & CLI-ERY-CIP-TET (5) & tetK, erm $B^{3}, e r m C, m s r A^{1}, l s a B^{1}$ & 4 & 2 & 0 & ES (1), SSTI (3), UTI (1) \\
\hline & TOB-CLI-ERY-MUP-TET (2) & tetK, ant $\left(4^{\prime}\right)-I a, \operatorname{erm} C, \operatorname{mup} A^{1}$ & 1 & 2 & 0 & ES (1), SSTI (1) \\
\hline \multirow{2}{*}{ t1381 (2) } & TET (1) & tetK & 0 & 1 & 0 & RTI (1) \\
\hline & CLI-ERY-CIP-TET (1) & tetK, erm C & 1 & 0 & 0 & RTI (1) \\
\hline t174 (1) & CIP-TET (1) & tetK & 1 & 0 & 0 & SSTI (1) \\
\hline t693 (1) & TET (1) & tetK & 0 & 0 & 0 & SSTI (1) \\
\hline $\mathrm{t} 1784(1)$ & ERY-TOB-TET (1) & tetK, ant $\left(4^{\prime}\right)-I a, m s r A$ & 1 & 0 & 1 & Blood (1) \\
\hline
\end{tabular}

a TET, tetracycline; ERY, erythromycin; CLI, clindamycin; CIP, ciprofloxacin; MUP, mupirocin; ${ }^{\mathrm{b}}$ A number in superscript reflects the number of isolates of the group that has the referred characteristic; ${ }^{\mathrm{C}}$ ES: epidemiological surveillance; RTI: respiratory tract infections; UTI: urinary tract infections; SSI: surgical site infection. 
A

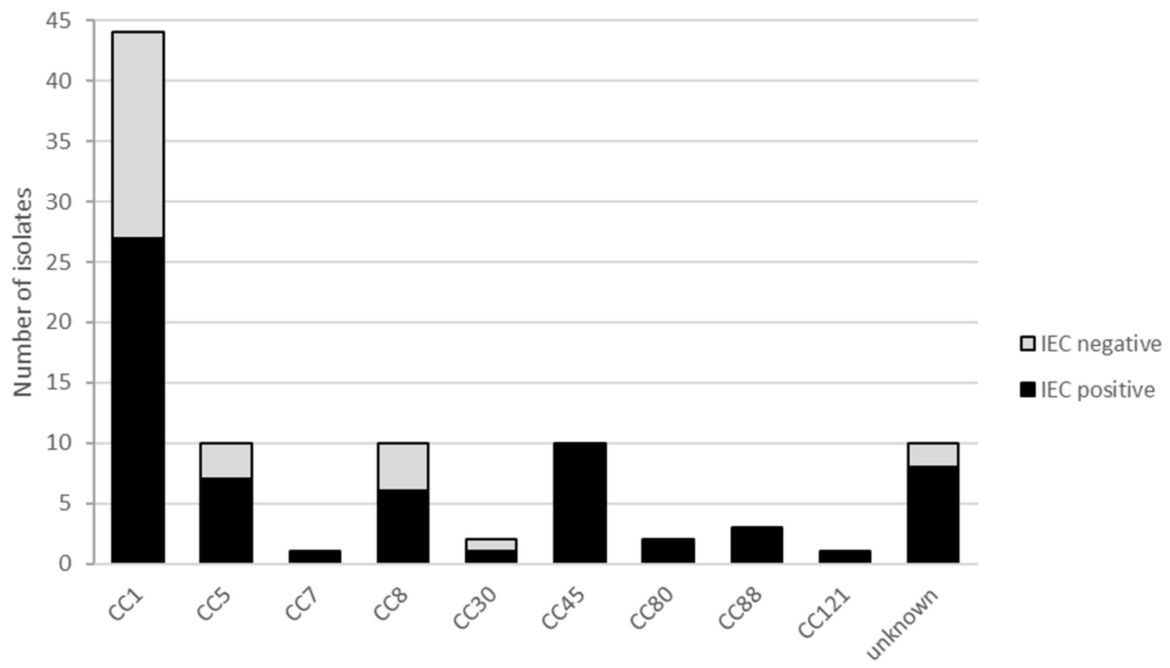

Clonal complexes (CC)

B

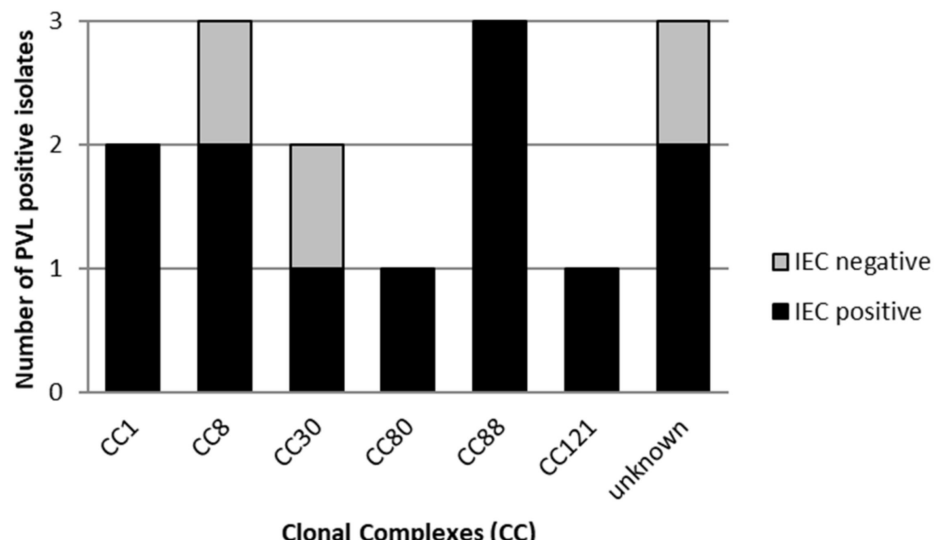

Figure 1. Presence of immune evasion cluster (IEC) among $\operatorname{Tet}^{\mathrm{R}}$-MRSA non-CC398 isolates: (A) Presence or absence of IEC according to the clonal complexes (CCs) of the isolates; (B) Presence or absence of the IEC in PVL-positive isolates according to their clonal complexes (CCs).
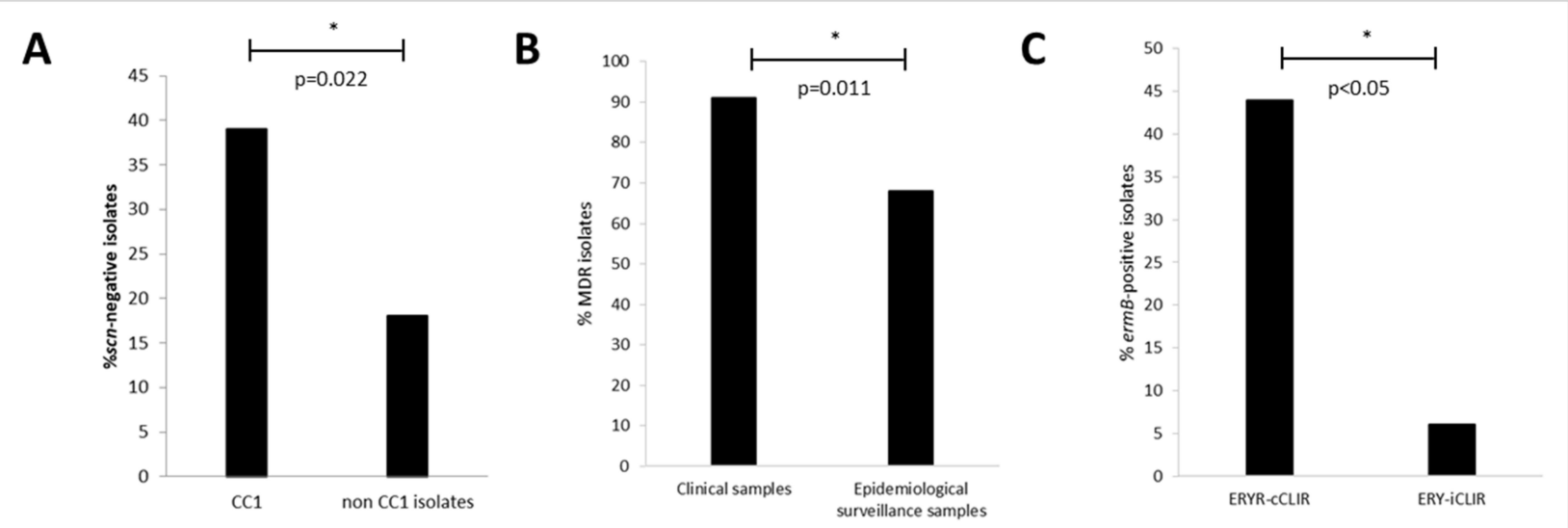

Figure 2. Statistically significant differences found in the characterisation of our $\mathrm{Tet}^{\mathrm{R}}$-MRSA nonCC398 isolates. (A) Absence of scn in CC1 and non-CC1 isolates; (B) MDR detection in clinical and epidemiological surveillance samples; (C) Detection of the ermB gene in erythromycin-clindamycin constitutive resistant $\left(E R Y^{\mathrm{R}}-\mathrm{cCLI}^{\mathrm{R}}\right)$ and erythromycin-clindamycin $\left(E R Y^{\mathrm{R}}-\mathrm{iCLI}^{\mathrm{R}}\right)$ inducible resistant isolates. ${ }^{*} p \leq 0.05$. 
A

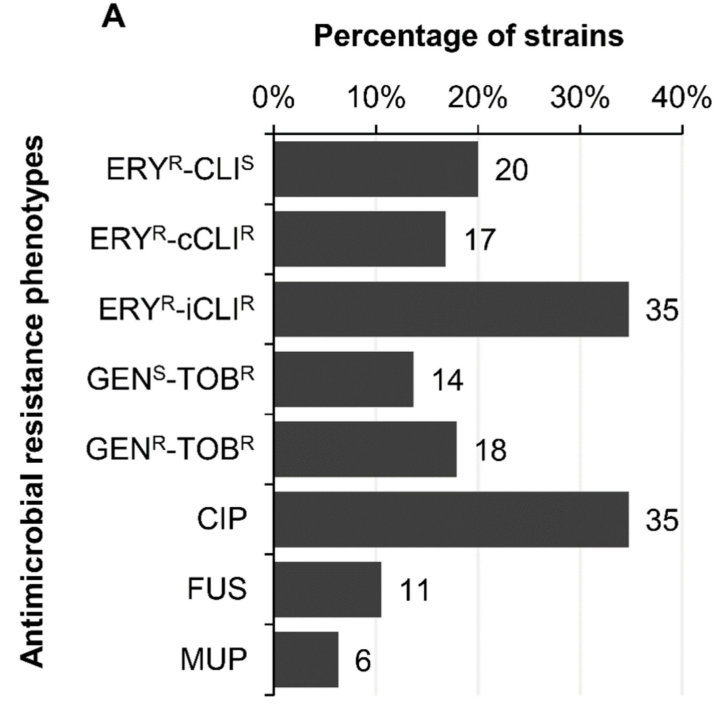

B

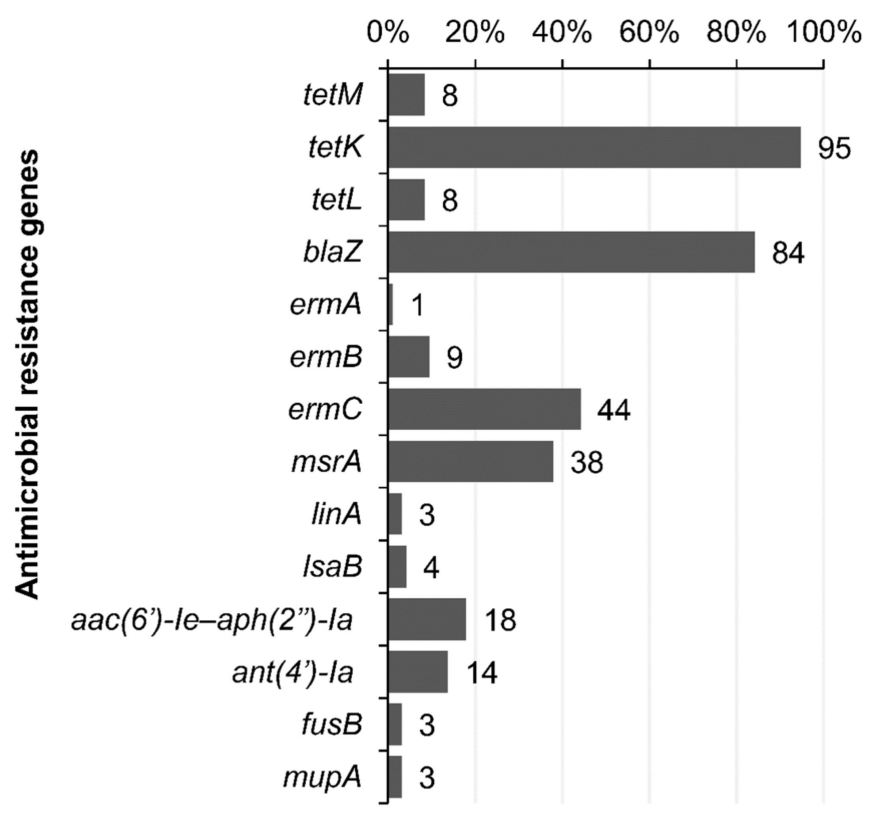

Figure 3. Antimicrobial resistance phenotype and genotype detected among $\operatorname{Tet}^{\mathrm{R}}$-MRSA nonCC398 isolates. (A) Antimicrobial resistance phenotype (ERY, erythromycin; CLI, clindamycin; CIP, ciprofloxacin; FUS, fusidic acid; MUP, mupirocin); (B) Antimicrobial resistance genotype.

There were statistically significant differences $(p=0.011)$ between clinical and ES MRSA isolates in terms of the MDR phenotype rates (Figure 2B). On the other hand, the differences when comparing the MDR phenotypes between the CC1 isolates and the remaining isolates were not statistically significant $(p>0.05)$.

None of the 95 analysed MRSA isolates was resistant to trimethoprim/sulfamethoxazole, vancomycin, teicoplanin, linezolid, daptomycin or chloramphenicol.

\subsection{Antimicrobial Resistance Phenotypes and Genotypes}

As known previously, all our MRSA isolates were mecA carriers, conferring methicillin resistance [14]. In addition, $84 \%$ of isolates $(n=80)$ harboured the blaZ gene, encoding a penicillinase (Figure $3 \mathrm{~B}$ ); the absence of the blaZ gene was more frequent among MRSA scnnegative isolates $(11 / 26,42.3 \%)$ than among scn-positive isolates $(4 / 69,5.8 \%)$. Moreover, $52.9 \%(9 / 17)$ of MRSA-CC1-scn-negative isolates were blaZ-negative, and only $7.4 \%(2 / 27)$ of CC1-scn-positive isolates were blaZ-negative (Figure 4).

All of the MRSA isolates were $\operatorname{Tet}^{\mathrm{R}}$, as it was a criterion for the isolates' selection, and $95 \%$ of them carried the tetK gene (Figure 3B), usually alone (82/95) or in combination with tetL (4/95), tetM (3/95) or both genes (1/95). The remaining $5 \%$ Tet $^{\mathrm{R}}$-MRSA isolates presented the tet $M$ gene alone (one isolate $\mathbf{2} 2849$ and one t1954) or tet $L$ alone (one t008 isolate); or both genes (two t17235 isolates).

Regarding macrolides and lincosamides, $72 \%$ of MRSA isolates showed resistance (Figure 3A), with three different phenotypes detected: (a) 19 MRSA isolates $(20 \%)$ showed resistance to erythromycin but not to clindamycin $\left(\mathrm{ERY}^{\mathrm{R}}{ }_{-} \mathrm{CLI}^{\mathrm{S}}\right)$; (b) 16 isolates $(17 \%)$ exhibited the constitutive erythromycin-clindamycin resistance $\left(E R Y^{R}-c_{C L I}{ }^{R}\right)$ phenotype; and (c) 33 isolates (35\%) presented the inducible erythromycin-clindamycin resistance

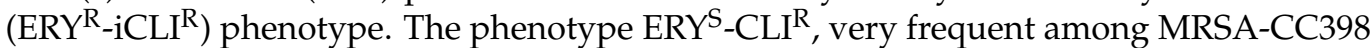
isolates [14], was not detected among the isolates of this study. The resistance genes related to macrolide-lincosamide resistance detected in this study are shown in Table 4. 


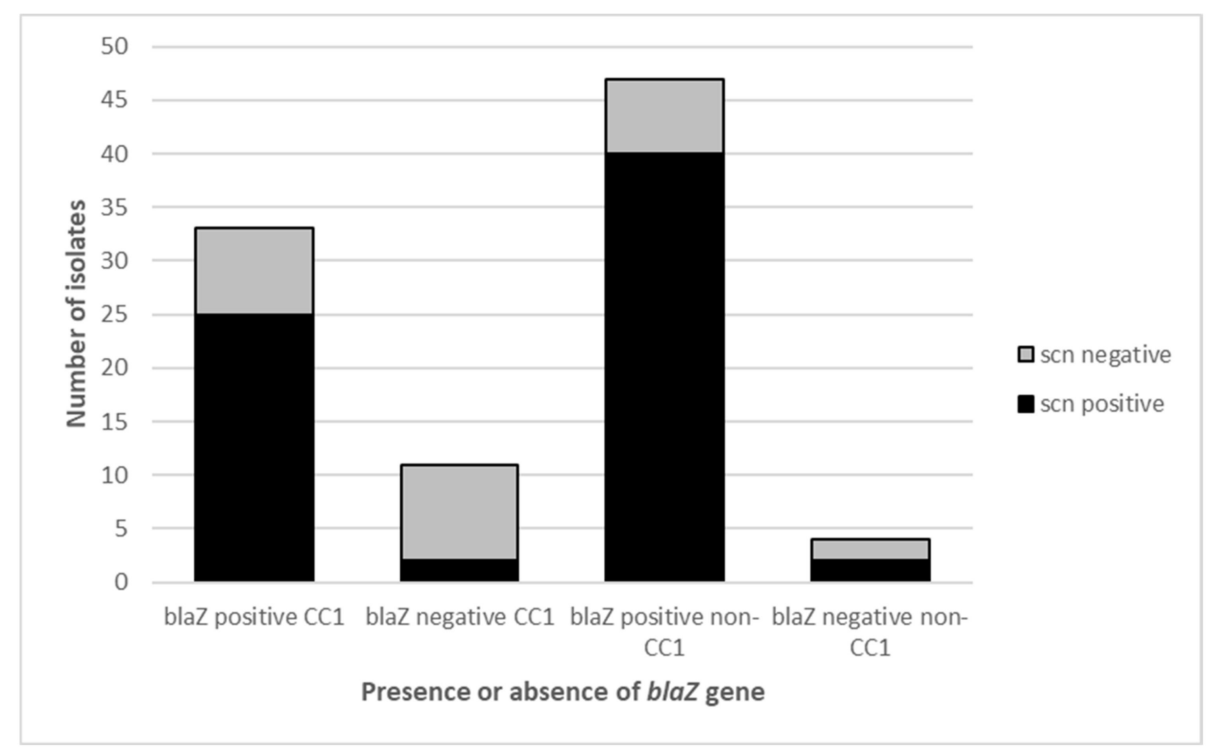

Figure 4. Presence or absence of the resistance blaZ gene in $\mathrm{CC} 1$ and non-CC1 tetracycline-resistant MRSA isolates according to the presence or absence of the IEC (scn gene).

Table 4. Macrolide-lincosamide resistance phenotypes among TetR-MRSA isolates and resistance genes detected $^{\mathrm{a}, \mathrm{b}}$.

\begin{tabular}{|c|c|c|c|c|c|c|c|c|c|c|}
\hline Phenotype & $\operatorname{erm} A$ & ermB & ermC & ermT & $m s r A$ & $\operatorname{lin} A$ & $\operatorname{lin} B$ & $l s a B$ & $v g a A$ & $\begin{array}{c}\text { No of } \\
\text { Isolates }\end{array}$ \\
\hline $\mathrm{ERY}^{\mathrm{R}}{ }_{-} \mathrm{CLI}^{\mathrm{S}}$ & - & - & - & - & + & - & - & - & - & 19 \\
\hline \multirow{8}{*}{$E R Y^{\mathrm{R}}-\mathrm{cCLI}^{\mathrm{R}}$} & - & - & + & - & + & - & - & - & - & 5 \\
\hline & - & - & + & - & - & - & - & - & - & 3 \\
\hline & - & + & + & - & - & - & - & - & - & 2 \\
\hline & - & + & - & - & + & - & - & - & - & 2 \\
\hline & + & + & - & - & + & + & - & + & - & 1 \\
\hline & - & + & - & - & + & - & - & + & - & 1 \\
\hline & - & + & + & - & - & - & - & + & - & 1 \\
\hline & - & - & + & - & + & + & - & - & - & 1 \\
\hline \multirow{6}{*}{$E R Y^{\mathrm{R}}-\mathrm{iCLI}{ }^{\mathrm{R}}$} & - & - & + & - & - & - & - & - & - & 25 \\
\hline & - & - & + & - & + & - & - & - & - & 4 \\
\hline & - & - & + & - & + & + & - & - & - & 1 \\
\hline & - & + & - & - & + & - & - & - & - & 1 \\
\hline & - & + & - & - & + & - & - & + & - & 1 \\
\hline & - & - & - & - & - & - & - & - & - & 1 \\
\hline
\end{tabular}

${ }^{a}$ Genes tested: ermA, ermB, erm $C, \operatorname{erm} T, m s r A, \operatorname{lin} A, \operatorname{lin} B, \operatorname{ls} a B$ and $\operatorname{vg} a A .{ }^{\mathrm{b}}$ Symbols: + : positive result; - : negative result.

Isolates with $E R Y^{\mathrm{R}}{ }_{-i C L I}{ }^{\mathrm{R}}$ phenotype carried more frequently the erm $\mathrm{C}$ gene $(91 \%)$ compared with $E R Y^{\mathrm{R}}-{ }_{-} \mathrm{CLI}{ }^{\mathrm{R}}$ isolates $(75 \%)$, but no statistically significant differences between both groups were found $(p>0.05)$. On the other hand, $\mathrm{ERY}^{\mathrm{R}}-\mathrm{cCLI}^{\mathrm{R}}$ isolates presented a higher rate of ermB gene (44\%) in comparison with $E R Y^{\mathrm{R}}-\mathrm{iCLI}^{\mathrm{R}}$ group $(6 \%)$, and, in this case, the statistical analysis showed a significant difference $(p<0.05)$ (Figure $2 \mathrm{C})$. The ermT and $\operatorname{lin} B /$ og aA genes were not detected among our ERYR and CLI ${ }^{\mathrm{R}}$ isolates, respectively.

Considering the aminoglycosides, $32 \%$ of isolates showed resistance to this group. More specifically, $14 \%$ of analysed isolates showed resistance to tobramycin alone (GEN ${ }^{\mathrm{S}}$ $\mathrm{TOB}^{\mathrm{R}}$ ) and $18 \%$ of isolates did it in combination with gentamicin $\left(\mathrm{GEN}^{\mathrm{R}}-\mathrm{TOB}^{\mathrm{R}}\right)$ (Figure $\left.3 \mathrm{~A}\right)$. The resistance gene found associated with the GEN ${ }^{\mathrm{S}}-\mathrm{TOB}^{\mathrm{R}}$ phenotype was in all cases ant $\left(4^{\prime}\right)-I a$, and for GEN ${ }^{\mathrm{R}}-\mathrm{TOB}^{\mathrm{R}}$ phenotype the $a a c\left(6^{\prime}\right)-I e-a p h\left(2^{\prime \prime}\right)-I a$ gene (Figure 3B).

The analysed non-CC398 MRSA isolates also presented resistance to ciprofloxacin in $35 \%$ of cases (33/95) (Figure 3A). In addition, three isolates presented the fusB gene 
for fusidic acid resistance, although ten isolates were resistant to this antimicrobial agent (11\%) (Figure 3A,B). For mupirocin, 6\% (6/95) of analysed isolates showed a resistance phenotype, and, of them, three isolates harboured the mupA gene (Figure 3A,B).

\subsection{Analysis of a Possible Relationship between MRSA CC1 and Pig Farming Density of Adjoining Region}

Spearman correlations between pig densities (estimated in pigs $/ \mathrm{km}^{2}$ per each region in which hospitals are located) and different proportions of MRSA CC1 or MRSA t127 or scn-negative MRSA (respect to total number of MRSA, S. aureus, Tet $^{\mathrm{R}}$-MRSA or MRSA non-CC398) were analysed. For each pair of variables studied, a non-statistically significant association was detected $(p>0.05)$. Considering the population densities of each region (inhabitants $/ \mathrm{km}^{2}$ ) and the proportions of MRSA CC1 analysed before, the results were similar, with no statistically significant association $(p>0.05)$.

\section{Discussion}

Tetracycline has been widely used for preventing and treating farm-animal infections, contributing with its use, and potential abuse, to the increase of antimicrobial resistance worldwide. Tet ${ }^{R}$ was evidenced as a good phenotypic marker for LA-MRSA detection in previous studies $[7,14]$ In the present study, the Tet ${ }^{R}$-MRSA non-CC398 isolates obtained using this phenotypic marker were exhaustively characterised. The most prevalent clonal complex, among Tet $^{\mathrm{R}}$-MRSA non-CC398, was CC1 (46\%) and the spa-type most frequently found was $\mathrm{t} 127$ (38 isolates). Thus, CC1-t127 isolates were identified in 14 out of the 17 participant hospitals. Considering the total of Tet $^{\mathrm{R}}-\mathrm{MRSA}$ isolates (including CC398, characterised in a previous study), CC1 was found in 19\% of them [14]. CC1 isolates were identified among Tet $^{\mathrm{R}}$ MRSA in other hospitals in the same range as those in our study $\left(12-19 \%\right.$ of Tet $^{\mathrm{R}}$-MRSA) $[7,23]$.

Some clones related to MRSA CC1, such as the well-known PVL producer USA400, have been broadly described [24]. Among our CC1 isolates, only one CC1-t127 was PVLpositive. Several PVL-negative CC1 clones have also been identified; the Western Australia (WA) MRSA-1 clone was first discovered in Australia in the 1980s, and, since then, these isolates have been detected in several European countries [24]. This PVL-negative clone, like USA400, is not usually associated with multidrug resistance profiles [25]; however, it typically carries blaZ and ermC antimicrobial resistance genes, and other virulence genes, including scn [26]. More recently, another PVL-negative MRSA-CC1 clone (different from the WA-MRSA-1) was identified in humans in Ireland with an alarming MDR profile and mupirocin resistance as a common feature [27]; this clone has been referred to as the European CC1-MRSA-IV clone [28]. These three MRSA CC1 clones share the feature that all of them present with SCCmec type IV, despite the fact that other MRSA CC1 clones can present SCCmec type V [24], mostly among swine-related isolates [20].

In our study, we found 11 isolates (10 characterised as $t 127$ and one as $\mathrm{t} 1381$ ) that could match the description of the WA-MRSA-1 clone (SCCmec IV, PVL-negative, ST1, blaZ-positive, ermC-positive and scn-positive), and one additional t127 isolate with the same features but a PVL producer. These potential WA-MRSA-1 isolates were mupirocinsusceptible and showed resistance to fewer families of antimicrobial agents in relation to the other three isolates (two t127 and one t2207) with features of the MDR-MRSA-CC1 clone (SCCmec IV, PVL-negative, and resistance to six-seven different groups of antimicrobial agents, including mupirocin).

Other CCs detected among our Tet ${ }^{\mathrm{R}}$-MRSA non-CC398 isolates were as follows: CC5 (11\%), CC8 (11\%), CC45 (11\%), CC88 (3\%), CC80 (2\%), CC7 (1\%) and CC121 (1\%). Analysing the use of tetracycline resistance to detect LA-MRSA isolates, in this study we identified clonal lineages previously related to both animals and humans, such as CC1, CC5, CC8 or CC30 [9]. However, other clones that are clearly associated with human infections (as CC45-t1081) [29,30] were also found. In this regard, it was important to analyse the presence of the IEC, since its absence has been associated with an animal origin $[7,20]$. 
IEC-negative isolates belonging to CC1, CC5, CC8 and CC30 were identified. These clonal lineages have been found in isolates from very diverse livestock animals (pigs, cattle, horses or poultry) $[9,12]$.

Even though no correlation between pig density and the cases of MRSA CC1 or MRSA t127 or scn-negative MRSA in hospitals was found in our study $(p>0.05)$, we cannot discard that this result could be biased by the small number of samples collected. Further studies should be performed, and tetracycline-susceptible isolates should be considered as well.

On the other hand, CC45-t1081 (the second spa-type most prevalent in our study) corresponds with the clone known as the Berlin clone [29-32]. This clone is usually associated with a health care and nosocomial transmission (especially linked to nursing homes) [30,31]. Remarkably, tetracycline resistance was identified in more than $20 \%$ of isolates belonging to the Berlin clone in one study carried out in several European countries [33] and in most MRSA CC45 isolates (71\%) obtained in one study in Poland [34]. In these studies, this phenotype was remarked for the microorganism's capacity to acquire multiple antimicrobial resistance determinants. This clone was also worryingly associated with toxigenic isolates [34].

Moreover, two of our t17235 isolates (new spa-type detected in this study) corresponded to ST2625. This ST was responsible for an outbreak in a Pediatric Intensive Care Unit in Italy in 2016 [35], and our t17235 isolates presented exactly the same resistance profile as those detected in the Italian hospital: tet M, tetL, mecA, blaZ and aac (6')-Ie-aph(2")-Ia genes. Another clonal lineage detected was CC121 in a PVL-producer isolate with a new spa-type (t17234). This CC is becoming an emergent and hypervirulent clone, with more than $90 \%$ of CC121 (ST121) isolates carrying the PVL virulence factor [36,37].

A high proportion of MDR phenotypes between the Tet ${ }^{\mathrm{R}}$-MRSA non-CC398 isolates studied were detected (86\%). Isolates belonging to CC1 did not show a significant increase or decrease in antimicrobial resistance compared to the remaining CCs $(p>0.05)$. Specifically, the rates of resistance genes found in CC1 isolates were: $100 \%$ mec $A, 100 \%$ tetK, 73\% blaZ, 56\% erm C, 29\% msr A, 11\% ermB, 9\% ant(4')-Ia , 4\% lsaB, 2\% tetL, 2\% mupA, and no isolates with tet $M$, erm $A$, ermT, $\operatorname{lin} A, \operatorname{lin} B, v g a A, \operatorname{aac}\left(6^{\prime}\right)$-Ie-aph(2")-Ia or fusB genes. Interestingly, more than half of the MRSA-CC1-scn-negative isolates lacked the blaZ gene $(52.9 \%)$, being a lower rate among MRSA-CC1-scn-positive isolates (7.4\%) or among the MRSA-scn-positive of other non-CC1 lineages (4.8\%). These data suggest that the MRSA strains with the scn gene (human adaptation marker) carry the blaZ gene in most cases, that is frequently absent among the MRSA isolates scn-negative (of potential animal origin). In this respect, a high rate of penicillin susceptibility (probably lacking blaZ) has been previously detected among animal S. aureus isolates [38,39]; moreover, scn-negative was a frequent characteristic of clinical methicillin-susceptible $S$. aureus blaZ-negative isolates in a multicentre Spanish study [40]. This potential link of scn-negative and blaZ-negative characteristics should be evaluated in the future in larger $S$. aureus collections, including MRSA/MSSA as well as scn-positive/negative isolates.

The important virulence factor PVL was found in $16 \%$ of isolates, and they belonged to very different clonal lineages (CC1, CC8, CC30, CC80, CC88, and CC121). Interestingly, PVL was identified in three IEC-negative isolates. This virulence gene is not frequently found in LA-MRSA isolates, but unfortunately its presence in animal isolates cannot be discounted [9].

Regarding the origin of MRSA-Tet ${ }^{\mathrm{R}}$ non-CC398 isolates obtained in this study, it is important to remark that few of them were recovered from invasive infections or from urinary or surgical infections ( $4.2 \%$ each); as a matter of fact, most of them were from SSTI, respiratory tract infections or epidemiological samples $(87.5 \%)$; this fact suggests that the dissemination routes for these tetracycline-resistant clonal lineages could be respiratory (inhalation) or contact transmission, as has also been indicated for MRSA-CC398 isolates [14]. These routes of transmission facilitate the colonisation of carriers that eventually could develop into cutaneous or respiratory infections. 


\section{Materials and Methods}

\subsection{Selection of Isolates}

A collection of 95 Tet $^{\mathrm{R}}$-MRSA non-CC398 isolates obtained in a previous study [14] was analysed in the present work. Isolates were recovered from clinical and epidemiological samples during a six-month period (2016) in a multicentre study of 20 participant Spanish hospitals (full names of hospitals in Table 1). In particular, 17 out of the 20 hospitals contributed with Tet $^{\mathrm{R}}$-MRSA non-CC398 isolates.

\subsection{Molecular Typing}

The molecular characterisation of spa-types (S. aureus protein A) was performed by PCR and sequencing for all 95 Tet $^{R}$-MRSA non-CC398 isolates, considering that 38 of them were typed in the previous study as t127-CC1 [18]. The spa gene sequences were analysed with $\operatorname{Ridom}^{\circledR}$ StaphType software (version 2.2.1). The sequence types (STs) of selected isolates and those with a new spa-type were determined by multilocus sequence typing (MLST) as described in https:/ / pubmlst.org/organisms / staphylococcus-aureus (accessed on 1 April 2021). For the remaining isolates, the clonal complex (CC) was assumed according to their spa-types. Determination of the SCCmec type was performed by PCR for isolates belonging to lineage CC1-t127 [41].

\subsection{Detection of the Immune Evasion Cluster System (IEC) and the Panton-Valentine Leucocidin $(P V L)$ Genes}

The presence of the IEC system was analysed through the detection of the scn gene, present in all types of IEC and used as a marker [42]. For the detection of lukF/lukS genes, which encode the PVL toxin, all isolates were subjected to PCR technique [43].

\subsection{Antimicrobial Susceptibility Testing}

Susceptibility to 13 antimicrobial agents, in addition to $\beta$-lactams and tetracycline, was performed using automatic methods and/or disk diffusion tests for all isolates. The antimicrobials tested were as follows: penicillin, oxacillin/cefoxitin, tetracycline, erythromycin, clindamycin, ciprofloxacin, trimethoprim/sulfamethoxazole, vancomycin, teicoplanin, linezolid, daptomycin, fusidic acid, mupirocin, gentamicin, tobramycin and chloramphenicol. Breakpoints used for interpretation were those according to the Clinical and Laboratory Standards Institute and/or the European Committee on Antimicrobial Susceptibility Testing, depending on hospitals. When a MRSA isolate was resistant to, at least, one agent of three or more different antimicrobial families, a multidrug resistance (MDR) phenotype was associated.

\subsection{Detection of Antimicrobial Resistance Genes}

The presence of the methicillin-resistance gene mecA was previously detected and confirmed in all MRSA-Tet ${ }^{\mathrm{R}}$ isolates [14]. In isolates with resistance phenotypes, the following antimicrobial resistance genes have been analysed in this study by PCR: tet $M$, tet $K$, and tet $L$ (tetracycline); erm $A, \operatorname{erm} B, \operatorname{erm} C, \operatorname{erm} T, \operatorname{msr} A, \operatorname{lin} A, \operatorname{lin} B, \operatorname{ls} a B$ and $v g a A$ (macrolides and/or lincosamides), ant (4')-Ia and aac(6')-Ie-aph(2")-Ia (aminoglycosides), mupA (mupirocin) and fusB (fusidic acid) [7,41]. Positive and negative controls from the University of La Rioja were used in all PCRs.

\subsection{Statistical Analysis}

Comparison of rates of interest were completed by using Pearson's Chi-square tests or Fisher's exact tests when some sample sizes were small (below five isolates). For estimating the association between the Tet ${ }^{\mathrm{R}}$-MRSA-CC1, Tet ${ }^{\mathrm{R}}$-MRSA-t127 or Tet ${ }^{\mathrm{R}}$-MRSA-noCC398scn-negative occurrence in hospitals and the pig density (pigs $/ \mathrm{km}^{2}$ ) in adjoining regions, Spearman rank correlations were performed.

All statistical analyses were made with the RStudio program (version 1.1.453) $(p<0.05$ was considered statistically significant). 


\section{Conclusions}

Tetracycline resistance is a good marker for the detection of MRSA CC398 isolates. Nevertheless, other clonal lineages related to livestock animals could also be detected using this marker; in this sense, scn-negative MRSA isolates belonging to CC1, CC5, CC8 and CC30 lineages, of potential animal origin, were frequently detected among non-CC398 Tet $^{\mathrm{R}}$-MRSA isolates (27.4\%). The knowledge of other Tet ${ }^{\mathrm{R}}$-MRSA genetic lineages is highly relevant, since most of them were MDR and some of them presented important virulence factors. Moreover, other human CC1 subpopulations (scn-positive) as well as the CC45 lineage (associated with facility centres/hospitals) were also detected among $\mathrm{Tet}^{\mathrm{R}}$-MRSA isolates. The use of tetracycline resistance for detection, not only of CC398, but of other LA-MRSA lineages and other relevant human lineages should be tracked in the future.

Author Contributions: C.T., M.Z. and C.A. conceived the study; S.C. performed most of the experimental work; C.L., L.R.-R., P.E. and A.C.-B. contributed to the experimental work; E.C., C.A., A.I.L.-C., J.C. (Javier Castillo), J.M.A.-G., L.T., J.C. (Jorge Calvo), C.M., M.N. and other members of the Study Group of Clinical LA-MRSA performed strain selection for this study and susceptibility testing of isolates; C.T., C.A., M.Z. and C.L. supervised the study; C.T., M.Z. and C.A. obtained financial support; S.C., C.L. and C.T. wrote the first version of the manuscript. All authors have read and agreed to the published version of the manuscript.

Funding: This work was supported by the project PID2019-106158RB-I00 of the MCIN/AEI/10.13039/ 501100011033 of Spain, and by the Sociedad de Enfermedades Infecciosas del Norte (SEINORTE).

Institutional Review Board Statement: Not applicable.

Informed Consent Statement: Not applicable.

Data Availability Statement: Not applicable.

Acknowledgments: We acknowledge the contribution of other members of the Spanish Study group of clinical LA-MRSA: José Leiva (Clínica Universidad de Navarra, Pamplona); Carmen Ezpeleta (Complejo Hospitalario de Navarra, Pamplona); Cristina Seral (Hospital Clínico Universitario Lozano Blesa, Zaragoza); Jorge Arribas, Carmen Navarro (Hospital de Alcañiz, Alcañiz, Teruel); Ana Betrán, Concepción López (Hospital de Barbastro, Barbastro, Huesca); Pilar Berdonces (Hospital de Galdakao, Galdakao, Vizcaya); Inés de Benito, Ana Belén Campo (Hospital de Sierrallana, Torrelavega, Cantabria); Antonina Arias, Blanca Fortuño (Hospital Ernest Lluch Martin, Calatayud, Zaragoza); Javier Pereira (Hospital Royo-Villanova, Zaragoza); Ana Milagro (Hospital San Jorge, Huesca); Carla Andrea Alonso (Hospital San Pedro, Logroño); Carmen Gimeno, Belén Ulibarri (Hospital Santiago Apóstol, Miranda de Ebro, Burgos); Anna Vilamala (Hospital Universitari de Vic, Vic, Barcelona); Andrés Canut, $\mathrm{M}^{\mathrm{a}}$ Luz Cordón (Hospital Universitario de Álava, Vitoria); Ledicia Álvarez, Gregoria Megías (Hospital Universitario de Burgos, Burgos); María Gomáriz (Hospital Universitario de Donostia, San Sebastián); Marina Fernández (Hospital Universitario Marqués de Valdecilla, Santander); Antonio Rezusta (Hospital Universitario Miguel Servet/IIS Aragón, Zaragoza), and Lorena LópezCerero (Hospital Universitario Virgen Macarena, Sevilla). Part of this work was presented at the 28th ECCMID, Madrid, Spain (poster P1727) and at the 29th ECCMID, Amsterdam, The Netherlands (poster P2707).

Conflicts of Interest: The authors declare no conflict of interest.

\section{References}

1. Lakhundi, S.; Zhang, K. Methicillin-resistant Staphylococcus aureus: Molecular characterization, evolution, and epidemiology. Clin. Microbiol. Rev. 2018, 31, e00020-18. [CrossRef] [PubMed]

2. Lozano, C.; Porres-Osante, N.; Benito, D.; Zarazaga, M.; Torres, C.; Rojo-Bezares, B.; Sáenz, Y.; Crettaz, J.; Olarte, I. Changes in genetic lineages, resistance, and virulence in clinical methicillin-resistant Staphylococcus aureus in a Spanish hospital. J. Infect. Chemother. 2013, 19, 233-242. [CrossRef] [PubMed]

3. Elstrøm, P.; Grøntvedt, C.A.; Gabrielsen, C.; Stegger, M.; Angen, Ø.; Åmdal, S.; Enger, H.; Urdahl, A.M.; Jore, S.; Steinbakk, M.; et al. Livestock-associated MRSA CC1 in Norway; introduction to pig farms, zoonotic transmission, and eradication. Front. Microbiol. 2019, 10, 139. [CrossRef] [PubMed]

4. Chen, C.; Wu, F. Livestock-associated methicillin-resistant Staphylococcus aureus (LA-MRSA) colonisation and infection among livestock workers and veterinarians: A systematic review and meta-analysis. Occup. Environ. Med. 2021, 78, 530-540. [CrossRef] 
5. Larsen, J.; Clasen, J.; Hansen, J.E.; Paulander, W.; Petersen, A.; Larsen, A.R.; Frees, D. Copresence of tet (K) and tet (M) in livestock-associated methicillin-resistant Staphylococcus aureus Clonal Complex 398 is associated with increased fitness during exposure to sublethal concentrations of tetracycline. Antimicrob. Agents Chemother. 2016, 60, 4401-4403. [CrossRef] [PubMed]

6. Stevens, M.J.A.; Stephan, R.; Johler, S. Draft genome sequence of Staphylococcus aureus S681, a tetracycline-sensitive livestockassociated methicillin-resistant Clonal Complex 398 Strain. Genome Announc. 2017, 5, e00805-17. [CrossRef]

7. Benito, D.; Lozano, C.; Rezusta, A.; Ferrer, I.; Vasquez, M.A.; Ceballos, S.; Zarazaga, M.; Revillo, M.J.; Torres, C. Characterization of tetracycline and methicillin resistant Staphylococcus aureus strains in a Spanish hospital: Is livestock-contact a risk factor in infections caused by MRSA CC398? Int. J. Med. Microbiol. 2014, 304, 1226-1232. [CrossRef]

8. Ruiz-Ripa, L.; Gómez, P.; Alonso, C.A.; Camacho, M.C.; De La Puente, J.; Fernández-Fernández, R.; Ramiro, Y.; Quevedo, M.A.; Blanco, J.M.; Zarazaga, M.; et al. Detection of MRSA of lineages CC130-mecC and CC398-mecA and Staphylococcus delphini-lnu (A) in magpies and cinereous vultures in Spain. Microb. Ecol. 2019, 78, 409-415. [CrossRef]

9. Butaye, P.; Argudín, M.A.; Smith, T.C. Livestock-associated MRSA and its current evolution. Curr. Clin. Microbiol. Rep. 2016, 3, 19-31. [CrossRef]

10. Lozano, C.; Fernández-Fernández, R.; Ruiz-Ripa, L.; Gómez, P.; Zarazaga, M.; Torres, C. Human mecC-carrying MRSA: Clinical implications and risk factors. Microorganisms 2020, 8, 1615. [CrossRef]

11. Aspiroz, C.; Lozano, C.; Vindel, A.; Lasarte, J.J.; Zarazaga, M.; Torres, C. Skin Lesion caused by ST398 and ST1 MRSA, Spain. Emerg. Infect. Dis. 2010, 16, 157-159. [CrossRef] [PubMed]

12. Fetsch, A.; Etter, D.; Johler, S. Livestock-associated meticillin-resistant Staphylococcus aureus_Current situation and impact from a One Health perspective. Curr. Clin. Microbiol. Rep. 2021, 8, 103-113. [CrossRef]

13. Hansen, J.E.; Ronco, T.; Stegger, M.; Sieber, R.N.; Fertner, M.E.; Martin, H.L.; Farre, M.; Toft, N.; Larsen, A.R.; Pedersen, K. LA-MRSA CC398 in dairy cattle and veal calf farms indicates spillover from pig production. Front. Microbiol. 2019, 10, 2733. [CrossRef]

14. Ceballos, S.; Aspiroz, C.; Ruiz-Ripa, L.; Reynaga, E.; Azcona-Gutiérrez, J.M.; Rezusta, A.; Seral, C.; Antoñanzas, F.; Torres, L.; López, A.R.; et al. Epidemiology of MRSA CC398 in hospitals located in Spanish regions with different pig-farming densities: A multicentre study. J. Antimicrob. Chemother. 2019, 74, 2157-2161. [CrossRef] [PubMed]

15. Lee, A.S.; De Lencastre, H.; Garau, J.; Kluytmans, J.; Malhotra-Kumar, S.; Peschel, A.; Harbarth, S. Methicillin-resistant Staphylococcus aureus. Nat. Rev. Dis. Prim. 2018, 4, 18033. [CrossRef]

16. Vignaroli, C.; Varaldo, P.E.; Camporese, A. Methicillin-resistant Staphylococcus aureus USA400 clone, Italy. Emerg. Infect. Dis. 2009, 15, 995-996. [CrossRef]

17. Petersen, A.; Stegger, M.; Heltberg, O.; Christensen, J.; Zeuthen, A.; Knudsen, L.; Urth, T.; Sorum, M.; Schouls, L.; Larsen, J.; et al. Epidemiology of methicillin-resistant Staphylococcus aureus carrying the novel mecC gene in Denmark corroborates a zoonotic reservoir with transmission to humans. Clin. Microbiol. Infect. 2013, 19, 16-22. [CrossRef]

18. Cooke, F.; Gkrania-Klotsas, E.; Howard, J.; Stone, M.; Kearns, A.; Ganner, M.; Carmichael, A.; Brown, N. Clinical, molecular and epidemiological description of a cluster of community-associated methicillin-resistant Staphylococcus aureus isolates from injecting drug users with bacteraemia. Clin. Microbiol. Infect. 2010, 16, 921-926. [CrossRef]

19. Otter, J.A.; Havill, N.L.; Boyce, J.M.; French, G.L. Comparison of community-associated meticillin-resistant Staphylococcus aureus from teaching hospitals in London and the USA, 2004-2006: Where is USA300 in the UK? Eur. J. Clin. Microbiol. Infect. Dis. 2009, 28, 835-839. [CrossRef]

20. Alba, P.; Feltrin, F.; Cordaro, G.; Porrero, M.C.; Kraushaar, B.; Argudín, M.A.; Nykäsenoja, S.; Monaco, M.; Stegger, M.; Aarestrup, F.; et al. Livestock-associated methicillin resistant and methicillin susceptible Staphylococcus aureus Sequence Type (CC)1 in European farmed animals: High genetic relatedness of isolates from Italian cattle herds and humans. PLoS ONE 2015, 10, e0137143. [CrossRef]

21. Franco, A.; Hasman, H.; Iurescia, M.; Lorenzetti, R.; Stegger, M.; Pantosti, A.; Feltrin, F.; Ianzano, A.; Porrero, M.C.; Liapi, M.; et al. Molecular characterization of spa type t127, sequence type 1 methicillin-resistant Staphylococcus aureus from pigs. J. Antimicrob. Chemother. 2011, 66, 1231-1235. [CrossRef] [PubMed]

22. Normanno, G.; Dambrosio, A.; Lorusso, V.; Samoilis, G.; Di Taranto, P.; Parisi, A. Methicillin-resistant Staphylococcus aureus (MRSA) in slaughtered pigs and abattoir workers in Italy. Food Microbiol. 2015, 51, 51-56. [CrossRef] [PubMed]

23. Lozano, C.; Rezusta, A.; Gómez, P.; Gómez-Sanz, E.; Báez, N.; Martin-Saco, G.; Zarazaga, M.; Torres, C. High prevalence of spa types associated with the clonal lineage CC398 among tetracycline-resistant methicillin-resistant Staphylococcus aureus isolates in a Spanish hospital. J. Antimicrob. Chemother. 2012, 67, 330-334. [CrossRef] [PubMed]

24. Monecke, S.; Coombs, G.; Shore, A.C.; Coleman, D.C.; Akpaka, P.; Borg, M.; Chow, H.; Ip, M.; Jatzwauk, L.; Jonas, D.; et al. A field guide to pandemic, epidemic and sporadic clones of methicillin-resistant Staphylococcus aureus. PLoS ONE 2011, 6, e17936. [CrossRef] [PubMed]

25. Earls, M.R.; Shore, A.C.; Brennan, G.I.; Simbeck, A.; Schneider-Brachert, W.; Vremeră, T.; Dorneanu, O.S.; Slickers, P.; Ehricht, R.; Monecke, S.; et al. A novel multidrug-resistant PVL-negative CC1-MRSA-IV clone emerging in Ireland and Germany likely originated in South-Eastern Europe. Infect. Genet. Evol. 2019, 69, 117-126. [CrossRef]

26. Coombs, G.W.; Monecke, S.; Pearson, J.C.; Tan, H.L.; Chew, Y.K.; Wilson, L.; Ehricht, R.; O’Brien, F.G.; Christiansen, K.J. Evolution and diversity of community-associated methicillin-resistant Staphylococcus aureus in a geographical region. BMC Microbiol. 2011, 11, 215. [CrossRef] 
27. Earls, M.R.; Kinnevey, P.M.; Brennan, G.I.; Lazaris, A.; Skally, M.; O'Connell, B.; Humphreys, H.; Shore, A.C.; Coleman, D.C. The recent emergence in hospitals of multidrug-resistant community-associated sequence type 1 and spa type t127 methicillin-resistant Staphylococcus aureus investigated by whole-genome sequencing: Implications for screening. PLoS ONE 2017, 12, e0175542. [CrossRef]

28. Earls, M.R.; Steinig, E.J.; Monecke, S.; Castruita, J.A.S.; Simbeck, A.; Schneider-Brachert, W.; Vremeră, T.; Dorneanu, O.S.; Loncaric, I.; Bes, M.; et al. Exploring the evolution and epidemiology of European CC1- MRSA-IV: Tracking a multidrug-resistant community-associated meticillin-resistant Staphylococcus aureus clone. Microb. Genom. 2021, 7, 000601. [CrossRef]

29. Gruteke, P.; Ho, P.L.; Haenen, A.; Lo, W.-U.; Lin, C.-H.; De Neeling, A.J. MRSA spa t1081, a highly transmissible isolate endemic to Hong Kong, China, in the Netherlands. Emerg. Infect. Dis. 2015, 21, 1074-1076. [CrossRef]

30. Tsao, F.-Y.; Kou, H.-W.; Huang, Y.-C. Dissemination of methicillin-resistant Staphylococcus aureus sequence type 45 among nursing home residents and staff in Taiwan. Clin. Microbiol. Infect. 2015, 21, 451-458. [CrossRef]

31. Van Gaalen, R.D.; Hopman, H.A.; Haenen, A.; Van Den Dool, C. Staff exchange within and between nursing homes in The Netherlands and potential implications for MRSA transmission. Epidemiol. Infect. 2017, 145, 739-745. [CrossRef] [PubMed]

32. Chow, A.; Lim, V.W.; Khan, A.; Pettigrew, K.; Lye, D.C.B.; Kanagasabai, K.; Phua, K.; Krishnan, P.; Ang, B.; Marimuthu, K.; et al. MRSA Transmission Dynamics Among Interconnected Acute, Intermediate-Term, and Long-Term Healthcare Facilities in Singapore. Clin. Infect. Dis. 2017, 64 (Suppl. S2), S76-S81. [CrossRef]

33. Cabrera, R.; Fernández-Barat, L.; Motos, A.; López-Aladid, R.; Vázquez, N.; Panigada, M.; Álvarez-Lerma, F.; López, Y.; Muñoz, L.; Castro, P.; et al. Molecular characterization of methicillin-resistant Staphylococcus aureus clinical isolates from the endotracheal tubes of patients with nosocomial pneumonia. Antimicrob. Resist. Infect. Control 2020, 9, 43. [CrossRef] [PubMed]

34. Kwapisz, E.; Garbacz, K.; Kosecka-Strojek, M.; Schubert, J.; Bania, J.; Międzobrodzki, J. Presence of egc-positive major clones ST 45, 30 and 22 among methicillin-resistant and methicillin-susceptible oral Staphylococcus aureus strains. Sci. Rep. 2020, 10, 18889. [CrossRef]

35. Ugolotti, E.; Di Marco, E.; Bandettini, R.; Biassoni, R. Genomic characterization of a paediatric MRSA outbreak by next-generation sequencing. J. Hosp. Infect. 2018, 98, 155-160. [CrossRef] [PubMed]

36. Rao, Q.; Shang, W.; Hu, X.; Rao, X. Staphylococcus aureus ST121: A globally disseminated hypervirulent clone. J. Med. Microbiol. 2015, 64, 1462-1473. [CrossRef]

37. Founou, R.C.; Founou, L.L.; Allam, M.; Ismail, A.; Essack, S.Y. Genomic characterisation of Staphylococcus aureus ST121 isolated from hospitalised patients in South Africa. S. Afr. Med. J. 2018, 108, 1007. [CrossRef]

38. Gharsa, H.; Slama, K.B.; Lozano, C.; Gómez-Sanz, E.; Klibi, N.; Ben Sallem, R.; Gómez, P.; Zarazaga, M.; Boudabous, A.; Torres, C. Prevalence, antibiotic resistance, virulence traits and genetic lineages of Staphylococcus aureus in healthy sheep in Tunisia. Vet. Microbiol. 2012, 156, 367-373. [CrossRef]

39. Attili, A.R.; Bellato, A.; Robino, P.; Galosi, L.; Papeschi, C.; Rossi, G.; Fileni, E.; Linardi, M.; Cuteri, V.; Chiesa, F.; et al. Analysis of the antibiotic resistance profiles in methicillin-sensitive $S$. aureus pathotypes isolated on a commercial rabbit farm in Italy. Antibiotics 2020, 9, 673. [CrossRef]

40. Mama, O.M.; Aspiroz, C.; Lozano, C.; Ruiz-Ripa, L.; Azcona, J.M.; Seral, C.; Cercenado, E.; López-Cerero, L.; Palacian, P.; Belles-Belles, A.; et al. Penicillin susceptibility among invasive MSSA infections: A multicentre study in 16 Spanish hospitals. J. Antimicrob. Chemother. 2021, 76, 2519-2527. [CrossRef]

41. Gómez-Sanz, E.; Torres, C.; Lozano, C.; Fernández-Pérez, R.; Aspiroz, C.; Ruiz-Larrea, F.; Zarazaga, M. Detection, molecular characterization, and clonal diversity of methicillin-resistant Staphylococcus aureus CC398 and CC97 in Spanish slaughter pigs of different age groups. Foodborne Pathog. Dis. 2010, 7, 1269-1277. [CrossRef] [PubMed]

42. Van Wamel, W.J.B.; Rooijakkers, S.H.M.; Ruyken, M.; van Kessel, K.P.M.; Van Strijp, J.A.G. The innate immune modulators staphylococcal complement inhibitor and chemotaxis inhibitory protein of Staphylococcus aureus are located on $\beta$-hemolysinconverting bacteriophages. J. Bacteriol. 2006, 188, 1310-1315. [CrossRef] [PubMed]

43. Lina, G.; Piémont, Y.; Godail-Gamot, F.; Bes, M.; Peter, M.-O.; Gauduchon, V.; Vandenesch, F.; Etienne, J. Involvement of Panton-Valentine leukocidin-producing Staphylococcus aureus in primary skin infections and pneumonia. Clin. Infect. Dis. 1999, 29, 1128-1132. [CrossRef] [PubMed] 